\title{
Development of hydrogels based on oxidized cellulose sulfates and carboxymethyl chitosan
}

\author{
Juliane Strätz (1) - Andrea Liedmann - Marie-Luise Trutschel • Karsten Mäder • \\ Thomas Groth $\cdot$ Steffen Fischer
}

Received: 22 January 2019/Accepted: 26 June 2019/Published online: 5 July 2019

(C) The Author(s) 2019

\begin{abstract}
Cellulose or chitosan represent highly abundant biopolymers possessing excellent biocompatibility that is required in tissue engineering. Both, cellulose and chitosan can be used to form hydrogels that can replace soft human tissues like cartilage. Hence, we developed here an approach to oxidize cellulose after sulfation, which was then crosslinked with carboxymethyl chitosan (CMCh). Sulfation was performed either by direct or acetosulfation reaching different sulfation degrees of $D S_{\text {Sulf }}=0.8-2.0$. Subsequently oxidation of cellulose sulfate (CS) was performed with sodium periodate, which yielded aldehyde contents of $D S_{\text {Ald }}=0.1-0.3$. Since oxidation requires the presence of vicinal hydroxyl groups in the anhydroglucose unit (AGU) of CS, higher
\end{abstract}

J. Strätz $(\bowtie) \cdot S$. Fischer

Institute of Plant and Wood Chemistry, Technische

Universität Dresden, Pienner Str. 19, 01737 Tharandt,

Germany

e-mail: juliane.straetz@tu-dresden.de

\footnotetext{
A. Liedmann · M.-L. Trutschel · K. Mäder · T. Groth Institute of Pharmacy, Martin Luther University HalleWittenberg, Wolfgang-Langenbeck-Str. 4, 06120 Halle (Saale), Germany

e-mail: thomas.groth@pharmazie.uni-halle.de

T. Groth

Interdisciplinary Center of Material Science and Interdisciplinary Center of Applied Sciences, Martin Luther University Halle-Wittenberg, 06099 Halle (Saale), Germany
}

sulfation degree as obtained by direct sulfation including hydroxyl groups at $\mathrm{C} 2$ and $\mathrm{C} 3$-position yielded lower aldehyde contents. On the contrary, regioselective sulfation at C6-position by acetosulfation was more suitable to achieve higher oxidation degrees of CS. Consequently, hydrogel formation obtained by chemical crosslinking of oxidized cellulose sulfate (oCS) with CMCh was fast within seconds when oxidation degree was high, but sulfation degree low. Moreover gel formation lasted almost $24 \mathrm{~h}$ when sulfation degree was high. It could also be shown that hydrogels based on oCS with a $D S_{\text {Ald }}$ of 0.28 or higher were stable for 25 days when incubated in phosphate-buffered saline (PBS) or Dulbeccos modified Eagle medium (DMEM). Studies with $\mathrm{pH}$ dependent fluorescent tracer molecules could show that the intrinsic $\mathrm{pH}$ value in hydrogels was slightly acidic ( $\sim$ pH 6.4) when they were incubated in PBS at $\mathrm{pH}$ 7.4. Mass transfer and homogeneity of the gel network was studied by NMR finding that diffusion of water molecules was not hindered inside the hydrogels.

Keywords Hydrogel - Tissue engineering · Oxidized cellulose sulfate - Carboxymethyl chitosan . Imine bond formation 


\section{Introduction}

1960, Wichterle and Lím (1960) described the first hydrogel based on hydroxyethyl methacrylate, which was the beginning of a new research era. Hydrogels are polymeric networks which can absorb and swell in water multiple times of their own dry weight and volume, respectively. They can be classified on the base of their cross-linking properties into physical and chemical hydrogels (Hoffman 2012). The connection of physical gels is reversible and consists of physical interactions such as formation of hydrogen bonds, ionic interactions or polymer chain entanglements (Caló and Khutoryanskiy 2015). On the contrary, the chemical junction is permanent and formed by covalent bonds. Today, hydrogels have numerous application possibilities ranging from wastewater treatment (Kumari and Chauhan 2011) over agriculture (Guilherme et al. 2010) to tissue engineering (Drury and Mooney 2003). Likewise the polymers used for gel formation are diverse and can be both of natural and synthetic origin (Wang et al. 2016). With regard to tissue engineering, hydrogels have to meet certain requirements like being non-toxic, biocompatible and bioactive (Shen et al. 2016), hence natural materials such as cellulose or chitosan have been already applied in recent studies (LogithKumar et al. 2016; Svensson et al. 2005).

Cellulose is the most abundant renewable polymer on earth and therefore low prized. The three hydroxy groups per AGU can be functionalized in manifold manner. However cellulose itself is not water soluble and only marginally swellable. The transformation into a water soluble derivate would facilitate the hydrogel synthesis. One such possibility is the implementation of sulfate groups (Wagenknecht et al. 1992). Not only the solubility increases this way, but also the bioactivity as it has been reported by Zhang et al. (2009) showing that cellulose sulfates can bind growth factors like fibroblast growth factor (b-FGF) and hereby promote the proliferation of cells.

Besides cellulose chitosan is another attractive raw material for hydrogel preparation because of its antimicrobial properties (Johney et al. 2017) and biodegradability (Muzzarelli 1997). Moreover chitosan as a polycation has, aside from hydroxy groups, an amino group per AGU which offers further synthetic possibilities. Chen and Fan (2008) used the polycationic nature of chitosan and synthesized a thermoset hydrogel system to form the gel in situ with the potential to serve as targeted drug carriers.

To crosslink chitosan the amino group can be used in a click reaction with an aldehyde or ketone to form an imine bond (Millan et al. 2015). The advantages of click reactions are their entire conversion to the product, their velocity and application to polysaccharides (Yang et al. 2016).

In this report we would like to present a synthesis to oxidize cellulose after sulfation, which was then crosslinked with CMCh to form a hydrogel via Schiff base. The gel components were characterized through Raman spectroscopy, NMR and size exclusion chromatography. The gel itself was characterized with rheological measurements as well as through stability studies in PBS and DMEM. Intrinsic pH during gel formation and diffusion of water inside the hydrogels were investigated with $\mathrm{pH}$ sensitive fluorescence probes and Benchtop NMR, respectively.

\section{Experimental}

Chemicals and reagents

Sulfite pulp $\left(D P_{\mathrm{W}}=1300\right)$ was received from Lenzing (Lenzing, Austria). Carboxymethyl chitosan $(D S=1$, degree of deacetylation $=94.2 \%)$, chitosan lactate and chitosan acetate were purchased from Heppe Medical Chitosan GmbH (Halle/Saale, Germany). Ethanol $99.5 \%$ denatured from Grüssing (Filsum, Germany), chlorosulfuric acid for synthesis and PBS from Merck (Darmstadt, Germany), dimethylformamide (DMF) $99 \%$ and sodium periodate $\geq 99.0 \%$ were purchased from Sigma Aldrich (Munich, Germany), ethylene glycol $\geq 99.5 \%$ p.a., sodium hydroxide and sodium acetate trihydrate were obtained from Carl Roth (Karlsruhe, Germany). The fluorescence dye SNARF-4F 5-(and-6)-carboxylic acid (SNARF) was purchased from Invitrogen (Darmstadt, Germany). DMEM was purchased from Lonza (Verviers, Belgium). DMF was dried over molecular sieve with a pore size of $3 \AA$. All other reagents were used without further purification. All aqueous solutions were prepared using deionized water. Dialysis membranes from Spectra/Por ${ }^{\circledR}$ had a molecular weight cut off of 100 Da to 500 Da and of 3500 Da. 
Sulfation of cellulose

Sulfation of cellulose was conducted by two methods referring to Zhang et al. (2011) with slight modifications. For both variations pretreatment was the following: Cellulose (2.50 g; $0.0154 \mathrm{~mol})$ was soaked in $125 \mathrm{ml} \mathrm{DMF}$ at ambient temperature for $24 \mathrm{~h}$. Dialysis was carried out using a standard regenerated cellulose membrane with a molecular weight cut off of $3.5 \mathrm{kDa}$.

Sulfation of cellulose The reaction agent consisting of DMF (25 ml) and chlorosulfuric acid $(0.0462 \mathrm{~mol}$, 3.0 eq.; 0.0693 mol, 4.5 eq.; 0.0924 mol, 6.0 eq.) was prepared while cooling in an ice bath. The sulfating agent was added dropwise to the soaked cellulose at room temperature (RT). After $3 \mathrm{~h}$ of vigorous stirring the now clear solution was poured in an ethanolic solution $(500 \mathrm{ml})$, which contained $\mathrm{NaOH}(14.3 \mathrm{~g}$, $0.358 \mathrm{~mol}$ ), $\mathrm{NaOAc} \cdot 3 \mathrm{H}_{2} \mathrm{O}$ (11.05 g, $\left.0.0812 \mathrm{~mol}\right)$ and $\mathrm{H}_{2} \mathrm{O}$ (26.5 ml) filled up to $500 \mathrm{ml}$ with ethanol (99\%). The precipitate had to rest at least $12 \mathrm{~h}$ before the supernatant was removed by centrifugation. Afterwards the sediment was washed two times with $4 \%$ ethanolic/aqueous (v:v; 1:1) sodium acetate solution $(100 \mathrm{ml})$. The product was dissolved in a minimum of $\mathrm{H}_{2} \mathrm{O}$ and the $\mathrm{pH}$ was adjusted to 8.0 with glacial acetic acid. Next, the cellulose sulfate was precipitated and dissolved two more times, then dialyzed and lyophilized.

Acetosulfation The reaction agent consisting of DMF (25 ml), chlorosulfuric acid $(0.0462 \mathrm{~mol}$, 3.0 eq.) and acetic anhydride ( $0.123 \mathrm{~mol}, 8.0$ eq.) was prepared while cooling in an ice bath. The sulfating agent was added dropwise to the soaked cellulose and heated to $50^{\circ} \mathrm{C}$, followed by $5 \mathrm{~h}$ of intense stirring at $50^{\circ} \mathrm{C}$. To quench the reaction the solution was poured in an ethanolic solution $(500 \mathrm{ml})$ which contained $\mathrm{NaOH}(14.3 \mathrm{~g}, 0.358 \mathrm{~mol}), \mathrm{NaOAc} \cdot 3$ $\mathrm{H}_{2} \mathrm{O}(11.05 \mathrm{~g}, 0.0812 \mathrm{~mol})$ and $\mathrm{H}_{2} \mathrm{O}(26.5 \mathrm{ml})$ filled up to $500 \mathrm{ml}$ with ethanol (99\%). The precipitate had to rest at least $12 \mathrm{~h}$ before the supernatant was removed by centrifugation. The sediment was washed two times with $4 \%$ ethanolic/aqueous (v:v; 1:1) sodium acetate solution $(100 \mathrm{ml})$. The product was then dissolved and stirred for $20 \mathrm{~h}$ at ambient temperature in $\mathrm{NaOH}(50 \mathrm{ml}, 1 \mathrm{~m} / \mathrm{l})$ for deacetylation, thereafter the $\mathrm{pH}$ was adjusted to 8.0 using glacial acetic acid. The cellulose sulfate was precipitated and dissolved two more times, then dialyzed and lyophilized.

Oxidation of cellulose sulfate

The oxidation method is based on Han et al. (2010). Cellulose sulfate $(1.5 \mathrm{~g})$ was dissolved in water $(60 \mathrm{ml})$ and sodium periodate $(1.5 \mathrm{~g} ; 0.007 \mathrm{~mol} ; 1$ weight equivalent) was added. The solution was stirred at ambient temperature under exclusion of light for $6 \mathrm{~h}$. By adding ethylene glycol $(1.5 \mathrm{ml}$; $0.027 \mathrm{~mol}$ ) and stirring for another hour the reaction was quenched. The oxidized cellulose sulfate was precipitated in ethanol $(300 \mathrm{ml})$, dialyzed using a cellulose ester membrane with a molecular weight cut off of $100 \mathrm{Da}$ to $500 \mathrm{Da}$ and lyophilized to obtain a white solid product.

Cross-linking of oxidized cellulose sulfate and carboxymethyl chitosan

Oxidized CS (20 mg) and CMCh (20 mg) were each dissolved in $1 \mathrm{ml} \mathrm{PBS}$ ( $\mathrm{KCl}(0.2 \mathrm{~g}), \mathrm{NaCl}(8.0 \mathrm{~g})$, $\mathrm{KH}_{2} \mathrm{PO}_{4}(0.19 \mathrm{~g})$ and $\mathrm{Na}_{2} \mathrm{HPO}_{4} \cdot 2 \mathrm{H}_{2} \mathrm{O}(0.765 \mathrm{~g})$ filled up to 11 with deionized water, afterwards the $\mathrm{pH}$ was adjusted with $\mathrm{NaOH}$ to 7.4). Then both solutions were mixed together $1: 1$ and stirred at ambient temperature with a stirring rod until a colorless gel was obtained.

\section{Hydrogel stability}

The oCS and CMCh were dissolved in PBS at a concentration of $20 \mathrm{mg} / \mathrm{ml}$. The hydrogels were created by mixing oCS and CMCh solution $1: 1$ to a final volume of $100 \mu$ l. The hydrogels were incubated $1 \mathrm{~h}$ at $37^{\circ} \mathrm{C}$ for crosslinking. Than the hydrogels were immersed, either with PBS or cell culture medium DMEM for up to 25 days. At each time point the solution was aspirated, remaining solution was eliminated with filter paper and the wet weight was determined.

Measurements

Fourier-transform (FT) Raman spectra were recorded on a Bruker MultiRam spectrometer with a liquid nitrogen cooled Ge diode as detector. All spectra were 
recorded over a range from 3500 to $150 \mathrm{~cm}^{-1}$ with a resolution of $4 \mathrm{~cm}^{-1}$.

The ${ }^{13} \mathrm{C}$-NMR spectra of $\mathrm{CS}$ in $\mathrm{D}_{2} \mathrm{O}$ were recorded at RT on Bruker Avance III $500 \mathrm{MHz}$ (Bruker, Etlingen, Germany) with a frequency of 125.76 MHz, pulse length of $12.05 \mu \mathrm{s}$, acq. time of $0.35 \mathrm{~s}$ and a relaxation delay of $3 \mathrm{~s}$. The ${ }^{1} \mathrm{H}-\mathrm{NMR}$ spectra of oxidized CS in $\mathrm{D}_{2} \mathrm{O}$ were recorded at RT on the same device with a frequency of $500.13 \mathrm{MHz}$, pulse length of $12.1 \mu \mathrm{s}$, acq. time of $3.3 \mathrm{~s}$ and a relaxation delay of $1 \mathrm{~s}$.

Size-exclusion chromatography (SEC) was performed on a SEC-7 (Jasco, Germany) equipped with UV detector (UV-975) and a RI detector (RI-930) under following conditions: columns: Suprema precolumn, Suprema 1000, Suprema 30; column temperature: $30.00^{\circ} \mathrm{C}$; eluent: $0.1 \mathrm{~mol} / 1 \quad \mathrm{NaNO}_{3} / 0.05 \%$ $\mathrm{NaN}_{3}$; flowrate: $1.000 \mathrm{ml} / \mathrm{min}$; standards: pullulan. All samples were filtered through a syringe filter (nylon, pore size $0.45 \mu \mathrm{m}$ ) ahead the injection.

Sulfur content was measured using the sulfur analyzer CS-580 by ELTRA. The degree of substitution $(D S)$ was calculated with Eq. 1 based on the determined sulfur content.

$$
D S_{\text {Sulf }}=\frac{162.1 \cdot S(\%)}{3207-102.1 \cdot S(\%)}
$$

The frequency sweep was conducted using an Ares-G2 (TA Instruments) under following conditions: $15 \mathrm{~mm}$ parallel plate; temperature: $25^{\circ} \mathrm{C}$; strain: $3.0 \times 10^{-3}$; logarithmic sweep; angular frequency: $0.1 \mathrm{rad} / \mathrm{s}$ to $100 \mathrm{rad} / \mathrm{s}$.

Determination of aldehyde content A blank consisting of hydroxylammonium chloride $(0.4 \mathrm{~mol} / \mathrm{l}$; $20 \mathrm{ml})$ and deionized water $(25 \mathrm{ml})$ was made and the $\mathrm{pH}$ was measured. Dialyzed oCS $(60.0 \mathrm{mg})$ was dissolved in deionized water $(25 \mathrm{ml})$ and the $\mathrm{pH}$ was adjusted to 7.0 using sodium hydroxide $(0.01 \mathrm{~mol} / \mathrm{l})$. After adding hydroxylammonium chloride $(0.4 \mathrm{~mol} / \mathrm{l}$; $20 \mathrm{ml}$ ), the reaction mixture was stirred for a minimum of three hours at RT. The released $\mathrm{HCl}$ was titrated with $\mathrm{NaOH}(0.01 \mathrm{~mol} / \mathrm{l})$ until the $\mathrm{pH}$ of the blank was reached. The amount of aldehyde given as $D S_{\text {Ald }}$ was calculated by the following equation:

$$
D S_{\mathrm{Ald}}=\frac{6 \cdot M_{\mathrm{C}} \cdot 0.01 \cdot t_{\mathrm{NaOH}} \cdot V_{\mathrm{NaOH}}}{C(\%) \cdot m}
$$

$M_{\mathrm{C}}$ : molar masse of carbon atom $(12.01 \mathrm{~g} / \mathrm{mol}), t_{\mathrm{NaOH}}$ : titer of $0.01 \mathrm{~mol} / \mathrm{l} \mathrm{NaOH}, V_{\mathrm{NaOH}}$ : volume of consumed $0.01 \mathrm{~mol} / 1 \mathrm{NaOH}$ solution in $\mathrm{ml}, C(\%)$ : carbon content of sample in $\%, m$ : mass of sample in $\mathrm{mg}$.

Detection of $\mathrm{pH}$ The $\mathrm{pH}$ was measured by fluorescence microscopy with the $\mathrm{pH}$-sensitive dye SNARF. This method has the advantage to detect a local $\mathrm{pH}$ inside the hydrogel. However, the $\mathrm{pH}$ range is limited by the dyes sensitivity range from $\mathrm{pH} 5$ to 7 (Schädlich et al. 2014). The dye was incorporated into the oCS $(200 \mu \mathrm{g} / \mathrm{ml})$ or CMCh $(100 \mu \mathrm{g} / \mathrm{ml})$ solution. The $\mathrm{pH}$ of the hydrogels prepared in PBS was measured once with the dye mixed in the cellulose solution and the once mixed in the $\mathrm{CMCh}$ solution to exclude a bias towards more neutral $\mathrm{pH}$ values in $\mathrm{CMCh}$ or towards more acidic values in the CS solutions. $10 \mu \mathrm{l}$ of the two solutions each were pipetted and stirred in a $100 \mu \mathrm{l}$ insert inside a glass vial. The vial was placed under the fluorescence microscope consisting of a light source (PhotoFluorII NIR), a microscope (Leica DM4000B) with Nuance EX fluorescence detector and Nuance Software. An image cube was detected with green (515-560 nm) and red (620-660 nm) excitation light. The two different excitations make it possible to compensate varying intensity and spectral broadening (Schädlich et al. 2014). The measurement was repeated without addition of SNARF to measure the background and auto-fluorescence of the hydrogels. The fluorescence spectrum was extracted from a region of interest in the image cube. The spectrum of the blank sample was subtracted. The ratio of the intensities is calculated with Eq. 3 from (Schädlich et al. 2014).

$$
\text { ratio }=\frac{I_{609 \mathrm{~nm}}^{g r}-I_{679 \mathrm{~nm}}^{r e d}}{I_{625 \mathrm{~nm}}^{g r}}
$$

From the ratio the $\mathrm{pH}$ can be calculated with the help of a calibration curve. The calibration was made with PBS with $20 \mu \mathrm{g} / \mathrm{ml} \mathrm{SNARF}$ and variation of $\mathrm{pH}$ with $\mathrm{NaOH}$ and $\mathrm{HCl}$.

Homogeneity and permeability of the hydrogels The transverse relaxation time distribution was characterized with a low-field benchtop Maran Ultra ${ }^{1} \mathrm{H}$ NMR spectrometer (Oxford Instruments, UK) including an air flow temperature control and a 3D imaging unit. Water, CMCh solution and the hydrogels were measured with a CPMG sequence consisting of a single $90^{\circ}$ radio frequency (rf) pulse followed by a 
series of $180^{\circ} \mathrm{rf}$ pulses with 20480 Echos, $2 \tau=135 \mu \mathrm{s}$ and $25 \mathrm{~s}$ recycle delay. The Windows Distributed EXPonential analysis software (WinDXP, Oxford Instruments, UK) was used to calculate $T_{2}$ distributions with 256 points in the relaxation time range from $10 \times 10^{-6} \mathrm{~s}$ to $20 \mathrm{~s}$.

The diffusion coefficients of the water molecules were measured with pulsed field gradient stimulated echo with gradient pulses of variable length. The diffusion time was $400 \mathrm{~ms}$. The maximal gradient strength of $0.922 \mathrm{~T} / \mathrm{m}$ was used.

\section{Results and discussion}

Synthesis of cellulose sulfates

The direct sulfation of cellulose is a quasihomogenous reaction. During the process of sulfation the cellulose becomes more and more soluble in DMF. The introduced sulfate group can be detected easily by FT-Raman spectroscopy based on the sulfate band at $1070 \mathrm{~cm}^{-1}$ (Fig. 1).

In contrast to direct sulfation, acetosulfation is a regioselective derivatization process. The acetyl groups work as protecting groups at $\mathrm{C} 2$ and $\mathrm{C} 3-$ position so that the sulfation proceeds only at the C6position of the AGU. In the ${ }^{13} \mathrm{C}-\mathrm{NMR}$ (Fig. 2) is the sulfation at $\mathrm{C} 6$ marked through the shift of the peak from $59.76 \mathrm{ppm}$ (unsubstituted, C6) to $66.09 \mathrm{ppm}$

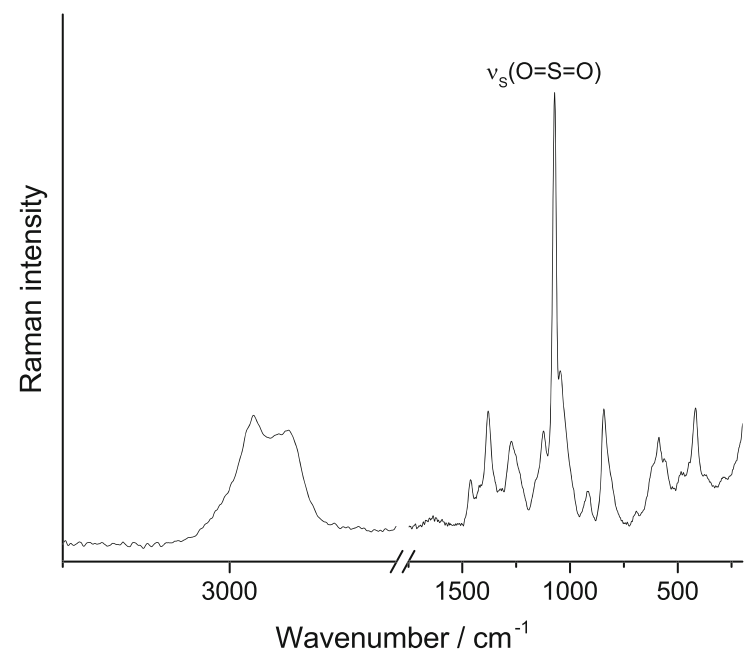

Fig. 1 Raman spectrum of cellulose sulfate with marked sulfate band at $1070 \mathrm{~cm}^{-1}$ (substituted. C6-S) (Nehls et al. 1994). Since the peaks for the substituted and unsubstituted C6 are visible, only a partial sulfation happened. This is confirmed by the $D S$ that is below 1 (Table 1 ).

The $D S_{\text {Sulf }}$ ranges as a function of the used amount of chlorosulfuric acid from 0.8 to 2.0 , specific values are given in Table 1.

Oxidation of cellulose sulfates

The introduction of aldehyde groups with sodium periodate is common in cellulose chemistry (Klemm et al. 1998). In order to perform the reaction, vicinal hydroxy groups are required. Due to the prior inserted sulfate groups, the oxidation is restricted to AGUs without sulfate groups at $\mathrm{C} 2$ or $\mathrm{C} 3$-position; otherwise the reaction cannot take place. That explains the low aldehyde content with a $D S_{\text {Ald }}$ of approximately 0.1 to 0.3 (Table 3 ), especially since the distribution of substituents using direct sulfation is not limited to the C6-position as compared to acetosulfation. The low aldehyde content is demonstrated in the ${ }^{1} \mathrm{H}-\mathrm{NMR}$ spectrum (Fig. 3); the aldehyde peak at $9.27 \mathrm{ppm}$ is very weak.

To increase the aldehyde content synthesis parameters can only be varied in a small range. The synthesis was carried out at RT in water as solvent. Raising the temperature would lead to a serious degradation of the oCS (Liu et al. 2012) whereas a decrease in temperature is limited because the reaction rates would slow down considerably (Varma and Kulkarni 2002) and water freezes at $0^{\circ} \mathrm{C}$. Also the approach to increase the quantity of used sodium periodate from 1 mass-eq. up to 3 mass-eq. of $\mathrm{NaIO}_{4}$ was not successful. Another possibility would be to increase the reaction time, however the amount of decomposed periodate would increase (Varma and Kulkarni 2002) and would not be available for oxidation.

Although sulfation and oxidation were carried out under mild conditions chain degradation was observed after sulfation and oxidation. This is due to the use of chlorosulfuric acid and sodium periodate, since both cause hydrolysis of the glycosidic bond. While the $M_{\mathrm{W}}$ decreased only after direct sulfation with 3.0 moleq. $\mathrm{HSO}_{3} \mathrm{Cl}$, it increased for all other sulfation reactions because the influence of the substitution of hydrogen atoms with sodium sulfate groups (Table 2) was higher than the chain degradation. After oxidation 
Fig. $2{ }^{13} \mathrm{C}$-NMR of cellulose sulfate synthesized via acetosulfation; key: CX-unsubstituted C-atom at position $\mathrm{X}$ in the $\mathrm{AGU}$, CX-S-substituted C-atom at position $\mathrm{X}$ in the $\mathrm{AGU}$

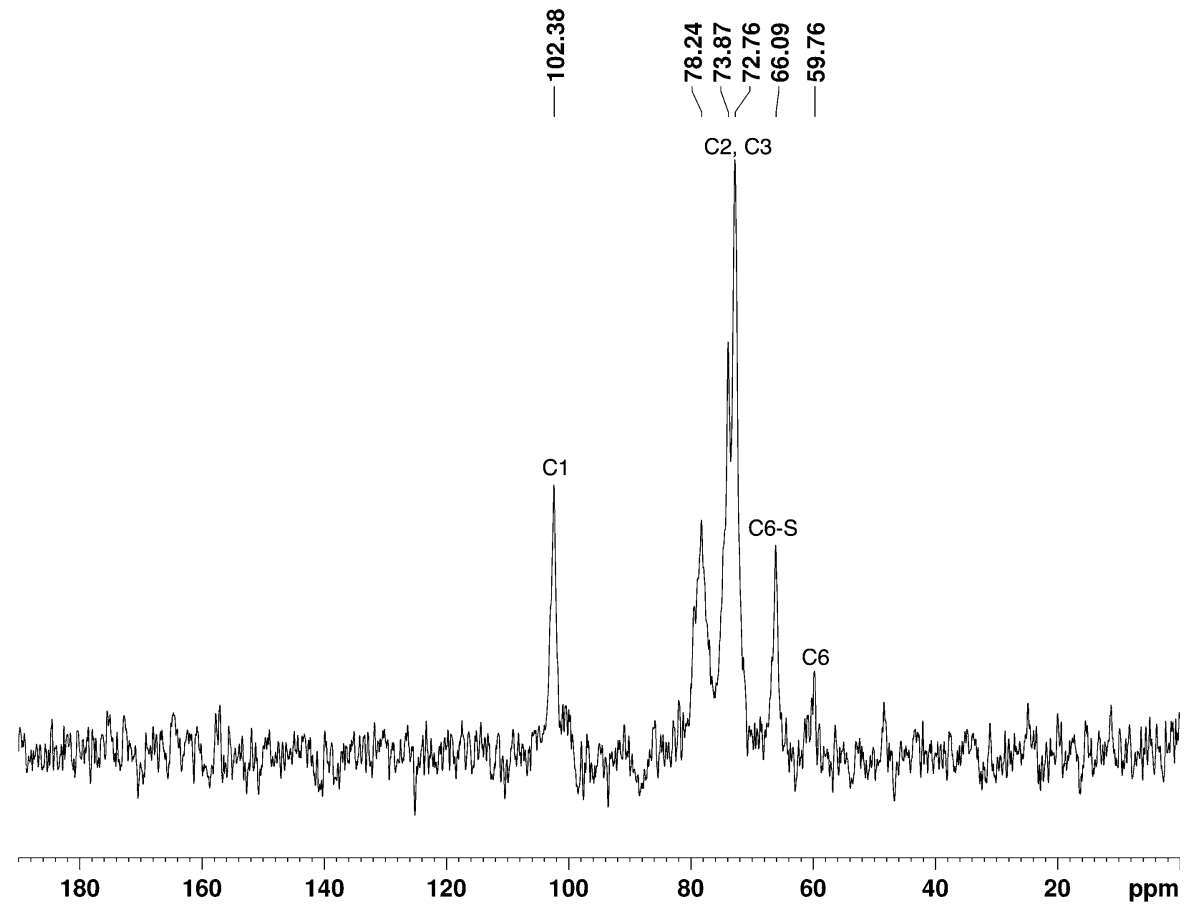

Table $1 D S$ values for synthesized cellulose sulfates starting from sulfite pulp in dependency on the molar ratio (mol-eq.) per AGU of chlorosulfuric acid and acetic acid anhydride $\left(\mathrm{Ac}_{2} \mathrm{O}\right)$; in the first line the result of the acetosulfation is presented, below the results for direct sulfation

\begin{tabular}{|c|c|c|c|}
\hline Mol-eq. $\mathrm{HSO}_{3} \mathrm{Cl} / \mathrm{Ac}_{2} \mathrm{O}$ & Temperature/ ${ }^{\circ} \mathrm{C}$ & Time / h & $D S_{\text {Sulf }}$ \\
\hline $3.0: 8.0$ & 50 & 5 & 0.8 \\
\hline 3.0:0 & RT & 3 & 1.1 \\
\hline $4.5: 0$ & RT & 3 & 1.6 \\
\hline $6.0: 0$ & RT & 3 & 2.0 \\
\hline
\end{tabular}

chain degradation was observed for all products. Concerning the occurrence of chain degradation sulfite pulp was used as starting material instead of microcrystalline cellulose to obtain higher molecular weights after functionalization, since the viscosity of hydrogels increases with increasing molecular weight (Zhou et al. 2008).

\section{Preparation of hydrogels}

First, for the formation of hydrogels by mixing oCS with a chitosan derivative three different derivatives were investigated: $\mathrm{CMCh}$, chitosan lactate and chitosan acetate. These derivatives were chosen because they are soluble under physiological conditions at $\mathrm{pH}$ 7.4, which is necessary for any application in tissue engineering. The hydrogel formation was carried out in the same manner analogous for all derivatives. The application of CMCh led to colorless, stable hydrogels (Fig. 4). In contrast oCS mixed with the other two derivatives under conditions of hydrogel formation no hydrogel was obtained. Instead a white solid of irregular shape was formed within $10 \mathrm{~s}$. Therefore CMCh was used in subsequent experimental work as a second gel component.

The cutout of the theoretical structure of the hydrogel in Fig. 5 shows oCS which is connected to $\mathrm{CMCh}$ by the formation of imine bonds. The quantity of possible cross-linkings is dependent on the number of aldehyde groups in oCS because they are much lower than the number of amine groups in chitosan. However, one should note that just a part of the aldehyde groups will be involved in cross-linking owing to the steric hindrance of the polymer chains. The sulfate groups have only an indirect influence on the network structure since they are not participating in cross-linking, yet the sulfate groups affect the aldehyde content. 
Fig. $3{ }^{1} \mathrm{H}$-NMR spectrum of oxidized cellulose sulfate, the aldehyde peak at $9.27 \mathrm{ppm}$ is marked

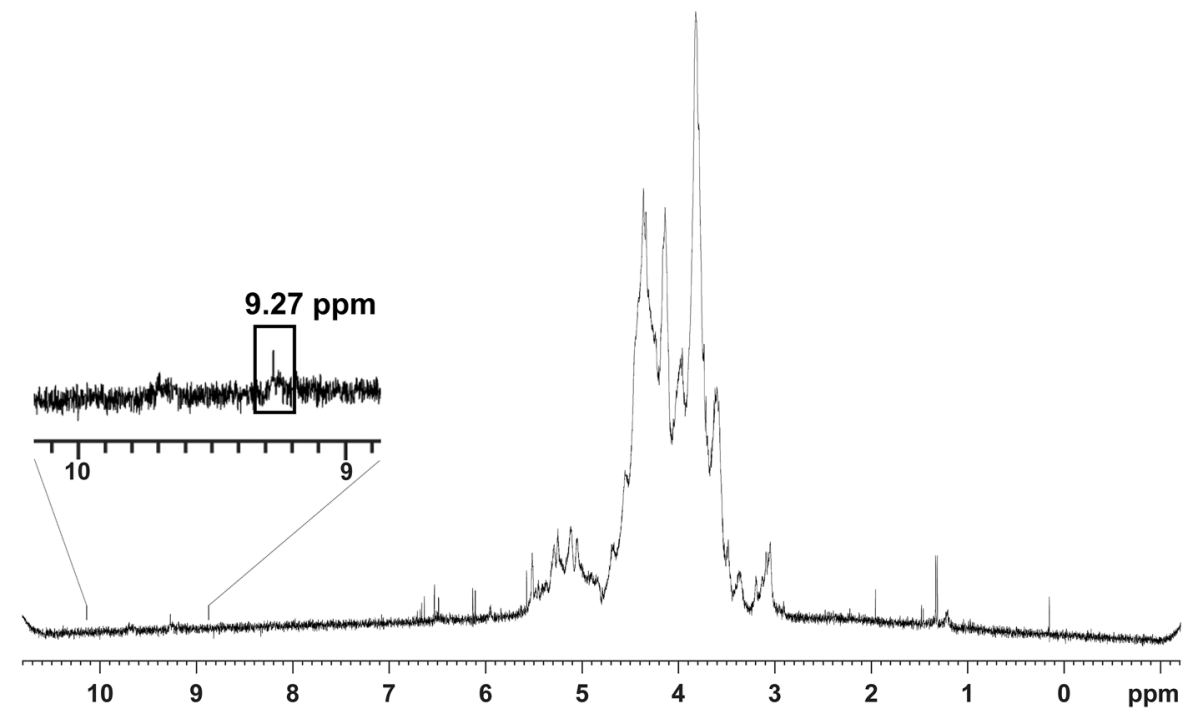

Table 2 Change in $M_{\mathrm{W}}$ after sulfation and oxidation, starting with a $M_{\mathrm{W}}$ of $2.1 \times 10^{5} \mathrm{~g} / \mathrm{mol}$ for the cellulose of sulfite pulp

\begin{tabular}{llr}
\hline Direct sulfation & $M_{\mathrm{W}}$ (sulfation) g/mol & $M_{\mathrm{W}}$ (oxidation) g/mol \\
\hline 3.0 mol-eq. $\mathrm{HSO}_{3} \mathrm{Cl}$ & $1.7 \times 10^{5}$ & $1.2 \times 10^{5}$ \\
6.0 mol-eq. $\mathrm{HSO}_{3} \mathrm{Cl}$ & $2.3 \times 10^{5}$ & $1.1 \times 10^{5}$
\end{tabular}

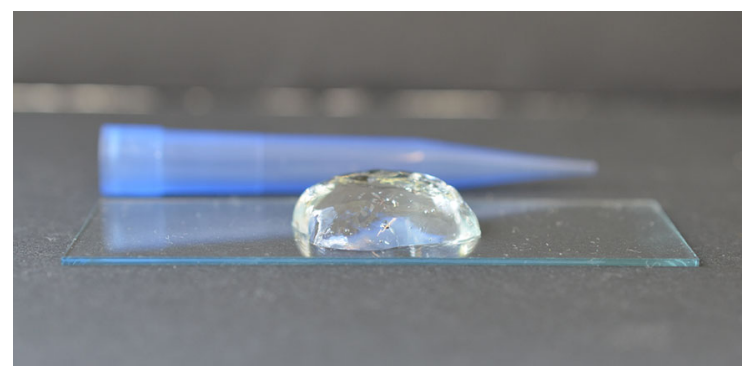

Fig. 4 The colorless hydrogel consists of oxidized cellulose sulfate $\left(D S_{\text {Sulf }}=1.1, \quad D S_{\text {Ald }}=0.33\right)$ and carboxymethyl chitosan

The kinetics of gel formation illustrated clearly its dependence on the aldehyde content. Was the $D S_{\text {Ald }}$ greater than 0.20 the gel was formed within five to ten seconds. In contrast to that, it took up to $24 \mathrm{~h}$ to develop a gel structure when the $D S_{\text {Ald }}$ was less than 0.20 . The gelation time was determined as the time required to form a coherent gel. Table 3 shows the relationship between $D S_{\text {Sulf }}$ and $D S_{\text {Ald }}$ and duration of gel formation.

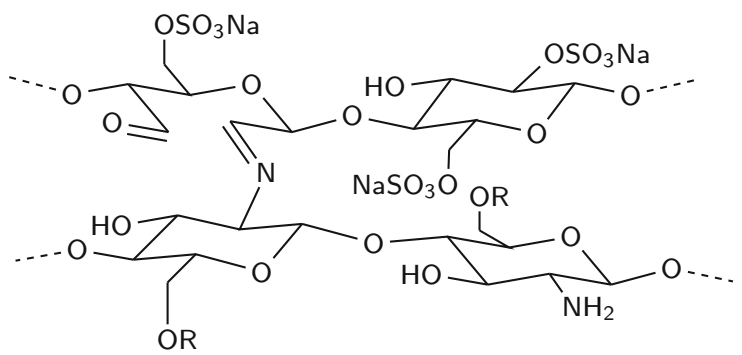

Fig. 5 Cutout of the theoretical structure of the synthesized hydrogel: an oxidized cellulose sulfate chain connected through an imine bond with a carboxymethyl chitosan chain; R: $\mathrm{CH}_{2} \mathrm{COOH}$

Table 3 Relationship between $D S_{\text {Sulf }}$ and $D S_{\text {Ald }}$ and the dependency on the time needed to form the hydrogel

\begin{tabular}{lll}
\hline$D S_{\text {Sulf }}$ & $D S_{\text {Ald }}$ & Time for gel formation \\
\hline 0.8 & 0.34 & $5 \mathrm{~s}$ \\
1.0 & 0.30 & $10 \mathrm{~s}$ \\
1.6 & 0.18 & $3 \mathrm{~h}$ \\
2.0 & 0.09 & $24 \mathrm{~h}$ \\
\hline
\end{tabular}


Besides the kinetics of gel formation, mechanical properties are of interest for the application of hydrogels. The reason is that cartilage and other soft tissues have to endure compressive strains and high stresses (Spiller et al. 2011). We used the frequency sweep to get information on the strength of the gel (Fig. 6). The gel shown in the diagram has a $D S_{\text {Sulf }}=$ 1.4 and $D S_{\text {Ald }}=0.11$ for the oCS and was prepared as described. Because of its low $D S_{\text {Ald }}$, it represents the minimum values which can be reached by all hydrogels. We observed an increase in the strength up to two days. The storage modulus at $\omega=10^{-1} \mathrm{rad} / \mathrm{s}$ doubles from $1.4 \mathrm{kPa}$ after one day of storage at RT to $2.8 \mathrm{kPa}$ after two days. In both cases is $G^{\prime}>G^{\prime \prime}$, which indicates that the gels represent viscoelastic solids and is a typical behavior for hydrogels. Moreover the value for $\tan \delta$ is between 0.2 and 0.3 which means the gels are stable against syneresis. So the gels will not lose incorporated liquids and instead of shrinking they will held their shape.

The use of two different routes of sulfation (acetosulfation and direct sulfation) yielded a large number of products that are summarized in Table 4 with information about $D S_{\text {Sulf }}, D S_{\text {Ald }}$ and route of sulfation either acetosulfation (A) or direct sulfation (D). These products were then later partly used for studies of gel stability in PBS or DMEM and investigations of intrinsic $\mathrm{pH}$ value and water mobility by spectroscopic methods.

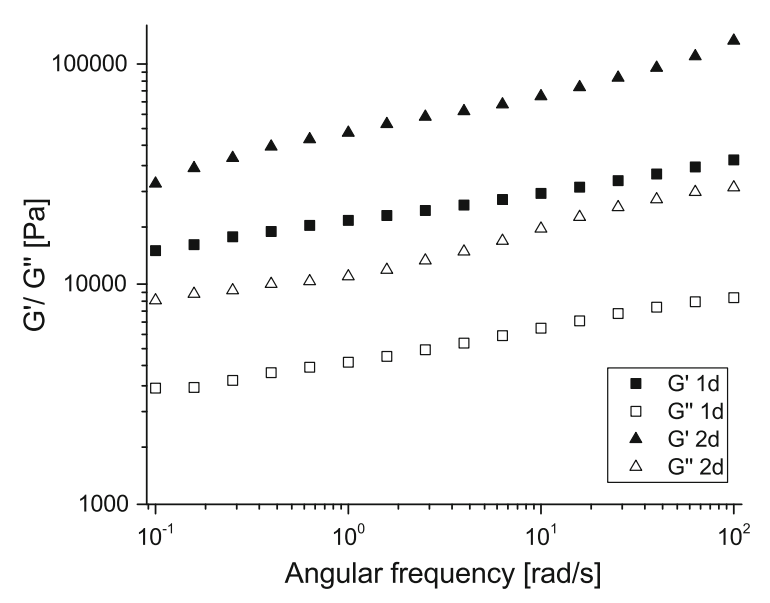

Fig. 6 Storage and loss modulus over angular frequency of a gel with $D S_{\text {Sulf }}=1.4$ and $D S_{\text {Ald }}=0.11$ after one and two days of storage at RT
Table 4 Overview of examined samples; route of sulfation either acetosulfation (A) or direct sulfation (D)

\begin{tabular}{lll}
\hline Route of sulfation & $D S_{\text {Sulf }}$ & $D S_{\text {Ald }}$ \\
\hline A & 0.8 & 0.21 \\
A & 0.8 & 0.34 \\
D & 1.1 & 0.28 \\
D & 1.1 & 0.33 \\
D & 1.5 & 0.20 \\
D & 1.6 & 0.18 \\
\hline
\end{tabular}

Hydrogel stability

Hydrogels crosslinked via imine bonds are susceptible to hydrolytic cleavage in aqueous conditions (Saito et al. 2007). Therefore, hydrogels made of different oCS were tested towards their stability in aqueous solutions. All hydrogels, which not form a hydrogel within $1 \mathrm{~h}$ or dissolve in PBS within $24 \mathrm{~h}$ were excluded. Fig. 7a shows hydrogels composed of oCS with different $D S_{\text {Ald }}$ incubated for 25 days in PBS. The wet weight of the hydrogels with $D S_{\text {Ald }}=0.33$ was most stable over time. At the end of the experiment about $55 \%$ of the hydrogel weight was remained. The hydrogel with $D S_{\text {Ald }}=0.18$ lost about $50 \%$ of weight within the first 3 days and was completely dissolved after 7 days. The hydrogels with $D S_{\text {Ald }}=0.28$ lost constantly weight over time and after 25 days only $10 \%$ of the hydrogels were left. Higher aldehyde content of oCS in the gels resulted in stable hydrogels for more than 25 days. Lower aldehyde content of the oCS resulted in hydrogels with lower stability in PBS. This is based on less crosslinkings due to the decreased aldehyde content, incomplete cross-linking after $1 \mathrm{~h}$ of gelation (Table 3) or both. The increase in stability of hydrogels in PBS due to the increase in oxidation degree was also described by Lü et al. (2010).

For further cell culture studies immersion of hydrogel in cell culture media like DMEM is required. The hydrogels showed different stability in PBS and DMEM (Fig. 7). Hydrogels with lower aldehyde content of oCS dissolved within 2 days $\left(D S_{\mathrm{Ald}}=0.18\right)$. Hydrogels of oCS with $D S_{\mathrm{Ald}}=$ 0.28 were stable for 14 days, whereas hydrogels with high aldehyde content of oCS $\left(D S_{\text {Ald }}=0.33\right)$ lost half of their weight within 14 days. However, more than 


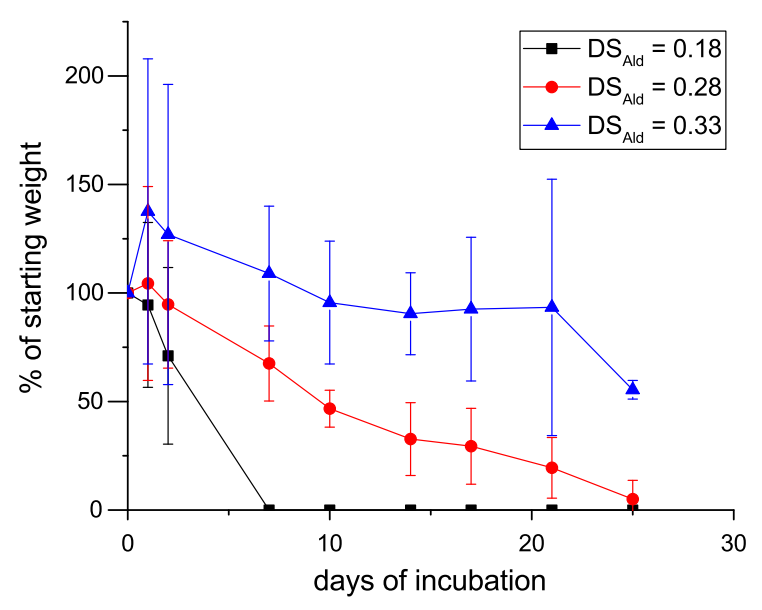

(a) PBS immersion

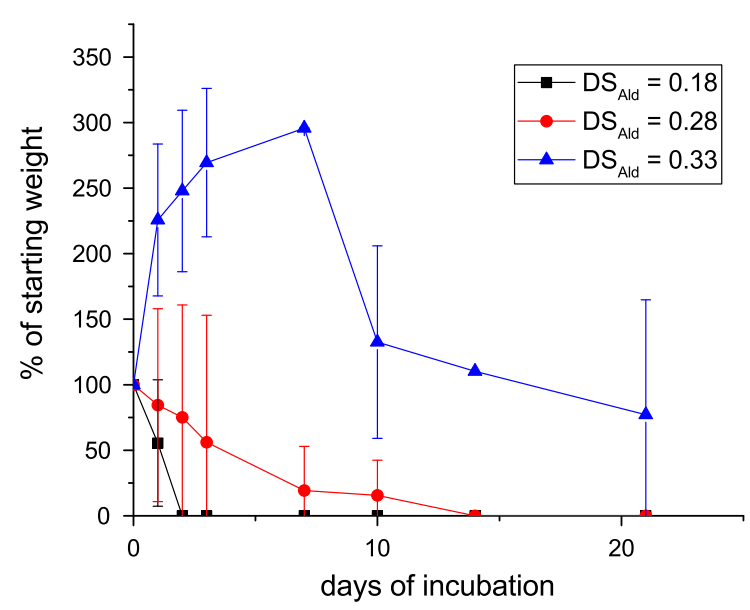

(b) DMEM immersion

Fig. 7 Wet weight of oCS-CMCh-hydrogels composed of oCS with different $D S_{\text {Ald }}$ incubated for 25 days in a PBS or b DMEM at $37^{\circ} \mathrm{C}$ in humid atmosphere; the oCS and $\mathrm{CMCh}$ solutions $(20 \mathrm{mg} / \mathrm{ml})$ were mixed $1: 1$ and rested for $1 \mathrm{~h}$ for gelation before immersion in either solvents

$80 \%$ of the hydrogel remained for a duration longer than 21 days stable.

Cell culture medium contains glucose, different amino acids and other substances, which cells need for metabolism and growth. The amino groups of the amino acids can compete with the amine groups of the $\mathrm{CMCh}$ and hence may destabilize existing imine bonds between CMCh and oCS (Elahipanah et al. 2017; Yang et al. 2014). This was probably the reason for the lower stability of hydrogels made of oCS with $D S_{\text {Ald }}=0.28$ and $D S_{\text {Ald }}=0.18$. This will eventually result in additional water influx to colloid osmotic swelling and disintegration of hydrogels (Hoffman 2012).

Intrinsic $\mathrm{pH}$ of hydrogels after cross-linking

The CS solutions majorly showed $\mathrm{pH}$ below the sensitive range of the SNARF, because of their acidic nature due to the presence of sulfate groups despite the presence of the sodium salt form. By contrast, the CMCh solution possessed a $\mathrm{pH}$ of 7.4. After mixing of both components as described, changes in the fluorescence intensity of SNARF were measured that permitted the calculation of $\mathrm{pH}$ value (see method section for details). In Fig. 8 the pH value is plotted against the sulfate content of oCS. On average the $\mathrm{pH}$ of the hydrogels is around 6.4, which means slightly acidic. The higher the sulfate content of the oCS the lower is the $\mathrm{pH}$ of the hydrogel. The two acetosulfated oCS hydrogels have nearly the same $D S_{\text {Sulf }}$. The less acidic $\mathrm{pH}$ corresponds to the hydrogel with the higher amount of aldehyde. The same observation has been made with the direct sulfated cellulose with a $D S_{\text {Sulf }}=1.1$.

Homogeneity and permeability of the hydrogels

The transverse relaxation time distribution monitors the mobility of the water molecules in the hydrogels. When their translational or rotational motions are restricted, the relaxation times shift to lower values. The exchange of protons between gelator and water

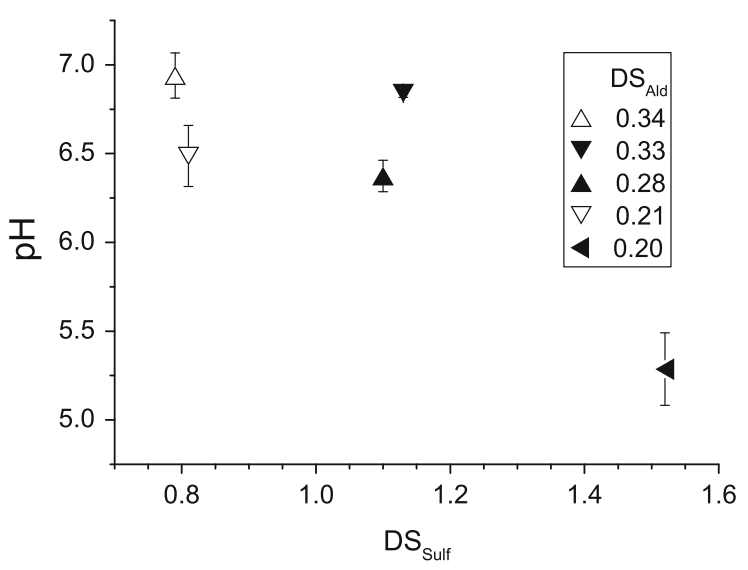

Fig. 8 The pH of the hydrogels prepared in PBS is plotted against the sulfate content; the filled symbols correspond to the direct sulfated cellulose and the open symbols to the acetosulfated cellulose 
(Hills et al. 1991) and local magnetic field inhomogenieties formed by gelators (Feng et al. 2014) can also cause slower transverse relaxation times. In inhomogeneous systems a broad distribution is seen. The distribution of $T_{2}$ of the gel network is for the majority of the hydrogels as narrow as water, but shifted to lower relaxation times (Fig. 9). From the small distribution follows a high homogeneity of the hydrogels, due to no syneresis (water outside the gel). The CMCh solution had the smallest $T_{2}$ distribution width. The peak is shifted to lower $T_{2}$ values compared to water due to the higher viscosity of the CMCh solution (Guevara et al. 2018). The two inhomogeneous hydrogel networks $\left(D S_{\text {Ald }}=0.20, \quad D S_{\text {Ald }}=0.28\right)$ showed a broad and bimodal distribution. Their spectra cover two or one order(s) of magnitude, respectively. There was no common feature concerning chemical treatment, $D S_{\text {Ald }}$ or $D S_{\text {Sulf }}$ between the two inhomogeneous hydrogels.

A small part of the water molecules were hindered in their mobility by the hydrogel forming components. Immobilized water at the glass surface was seen around $300 \mu \mathrm{s}$ in all samples (not shown), including the pure water sample (Bastrop et al. 2011). The small peaks around $200 \mathrm{~ms}$ and at $380 \mathrm{~ms}$ in the hydrogel $D S_{\text {Ald }}=0.21$ could origin in attached water molecules or hydrogen of oCS or CMCh.

The homogeneous $T_{2}$-distributions of the majority of water molecules were fitted with a log-normal distribution and the mode was used to compare the hydrogels. The transverse relaxation time and its distribution correlated with the mesh size of the

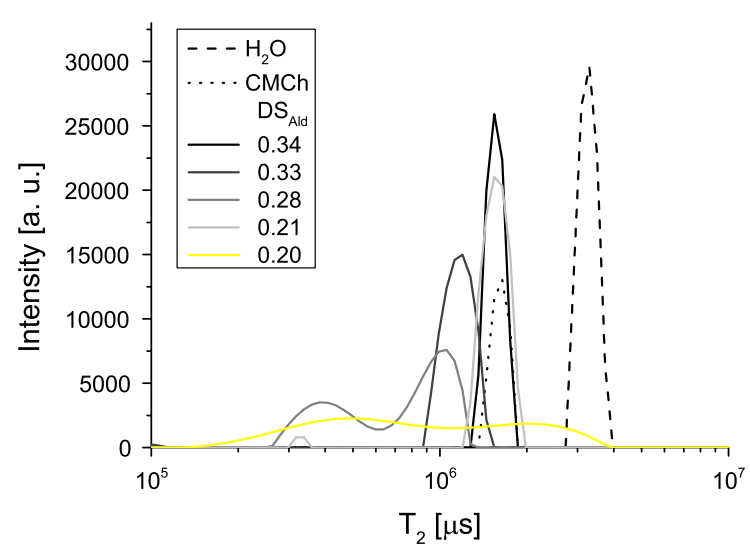

Fig. 9 The distribution of the $T_{2}$ shows the homogeneity of the gel network; the water and CMCh solution is also plotted for comparison hydrogel (Pescosolido et al. 2012). One could expect for higher amounts of aldehyde groups a denser hydrogel with lower $T_{2}$ due to more magnetic inhomogeneities or exchange with more rigid gelator protons. There was no correlation between the amount of aldehyde and the mode of the $T_{2}$ found, because the $T_{2}$ is $1.5 \mathrm{~s}$ for two of three homogeneous hydrogels. $D S_{\text {Ald }}$ seems to influence the speed of hydrogel formation, but the density of the network varies not enough to see a clear impact on the $T_{2}$.

The diffusion coefficients of water in the gels are the same as in pure water in the range of the measurement accuracy. The diffusion of water molecules is not hindered by the hydrogels. Also in peptide based hydrogels there was no impact found on the water diffusion but on the $T_{2}$ (Feng et al. 2014).

\section{Conclusions}

The synthesis of oCS with a $D S_{\text {Sulf }}$ ranging from 0.8 to 2.0 and a $D S_{\text {Ald }}$ up to 0.34 was shown. The successful crosslinking of oCS and CMCh was demonstrated by obtaining colorless hydrogels and the relation between sulfation degree and time of gelation was discussed. The stability of the hydrogels in PBS and DMEM increased with the $D S_{\text {Ald }}$. We could also illustrate the homogeneity of the gel network by the $T_{2}$ distribution and proof that the diffusion of water molecules is not hindered by the hydrogel. An obvious problem was the lower $\mathrm{pH}$ value inside the hydrogels that is probably related to the presence of sulfate groups. Overall, the hydrogels developed here will undergo further studies to test their applicability to accommodate cells for future use as in situ gelling, injectable hydrogels.

Acknowledgments We thank Harald Rohm and Norbert Raak for the possibility and support to do the rheological measurements, Erica Brendler for the NMR measurements and Thomas Heinze for the size exclusion chromatography. This work was financially supported by DFG; project: In situ gelierende Hydrogele zur Regeneration von Knorpel; Grant Numbers:FI755/10-1; GR1290/11-1; MA1648/11-1.

Open Access This article is distributed under the terms of the Creative Commons Attribution 4.0 International License (http:// creativecommons.org/licenses/by/4.0/), which permits unrestricted use, distribution, and reproduction in any medium, provided you give appropriate credit to the original author(s) and the source, provide a link to the Creative Commons license, and indicate if changes were made. 


\section{References}

Bastrop M, Meister A, Metz H, Drescher S, Dobner B, Mäder K, Blume A (2011) Water dynamics in bolaamphiphile hydrogels investigated by ${ }^{1} \mathrm{~h} \mathrm{nmr}$ relaxometry and diffusometry. J Phys Chem B 115:14-22

Caló E, Khutoryanskiy VV (2015) Biomedical applications of hydrogels: A review of patents and commercial products. Eur Polym J 65(Supplement C):252-267

Chen H, Fan M (2008) Novel thermally sensitive ph-dependent chitosan/ carboxymethyl cellulose hydrogels. J Bioact Compat Polym 23(1):38-48

Drury JL, Mooney DJ (2003) Hydrogels for tissue engineering: scaffold design variables and applications. Biomaterials 24(24):4337-4351

Elahipanah S, O’Brien PJ, Rogozhnikov D, Yousaf MN (2017) General dialdehyde click chemistry for amine bioconjugation. Bioconjugate Chem 28(5):1422-1433

Feng Y, Taraban MB, Yu YB (2014) Linear dependence of the water proton transverse relaxation rate on the shear modulus of hydrogels. Chem Commun 50:12,120

Guevara MAL, Torres YM, Naranjo JCG, Suárez NR, Beyries LCS, Feliu MAM, Boada TS, Reyes ICR, Philippé J (2018) Plasma Dynamic viscosity determined by NMR. Appl Magn Reson 49(10):1075-1083

Guilherme MR, Reis AV, Paulino AT, Moia TA, Mattoso LH, Tambourgi EB (2010) Pectin-based polymer hydrogel as a carrier for release of agricultural nutrients and removal of heavy metals from wastewater. J Appl Polym Sci 117(6):3146-3154

Han S, Lee M, Kim BK (2010) Crosslinking reactions of oxidized cellulose fiber. i. reactions between dialdehyde cellulose and multifunctional amines on lyocell fabric. J Appl Polym Sci 117(2):682-690

Hills BP, Cano C, Belton PS (1991) Proton nmr relaxation studies of aqueous polysaccharide systems. Macromolecules 24:2944-2950

Hoffman AS (2012) Hydrogels for biomedical applications. Adv Drug Deliv Rev 64:18-23

Johney J, Eagappan K, Ragunathan RR (2017) Microbial extraction of chitin and chitosan from pleurotus spp, its characterization and antimicrobial activity. Int $\mathrm{J}$ Curr Pharm Res 9(1):88-93

Klemm D, Philipp B, Heinze T, Heinze U, Wagenknecht W (1998) Comprehensive cellulose chemistry, volume 2 functionalization of cellulose, vol 2. Wiley-VCH, Weinheim

Kumari M, Chauhan GS (2011) Adsorption capacity, kinetics, and mechanism of copper(ii) uptake on gelatin-based hydrogels. J Appl Polym Sci 119(1):363-370

Liu X, Wang L, Song X, Song H, Zhao JR, Wang S (2012) A kinetic model for oxidative degradation of bagasse pulp fiber by sodium periodate. Carbohydr Polym 90(1):218-223

LogithKumar R, KeshavNarayan A, Dhivya S, Chawla A, Saravanan S, Selvamurugan N (2016) A review of chitosan and its derivatives in bone tissue engineering. Carbohydr Polym 151:172-188
Lü S, Liu M, Ni B (2010) An injectable oxidized carboxymethylcellulose/n-succinyl-chitosan hydrogel system for protein delivery. Chem Eng J 160(2):779-787

Millan C, Cavalli E, Groth T, Maniura-Weber K, Zenobi-Wong M (2015) Engineered microtissues formed by schiff base crosslinking restore the chondrogenic potential of aged mesenchymal stem cells. Adv Healthcare Mater 4(9): 1348-1358

Muzzarelli RAA (1997) Human enzymatic activities related to the therapeutic administration of chitin derivatives. Cell Mol Life Sci 53(2):131-140

Nehls I, Wagenknecht W, Philipp B, Stscherbina D (1994) Characterization of cellulose and cellulose derivatives in solution by high resolution ${ }^{13} \mathrm{c}-\mathrm{nmr}$ spectroscopy. Prog Polym Sci 19(1):29-78

Pescosolido L, Feruglio L, Farra R, Fiorentino S, Colombo I, Coviello T, Matricardi P, Hennink WE, Vermonden T, Grassi M (2012) Mesh size distribution determination of interpenetrating polymer network hydrogels. Soft Matter 8:7708

Saito H, Hoffman AS, Ogawa HI (2007) Delivery of doxorubicin from biodegradable peg hydrogels having schiff base linkages. J Bioact Compat Polym 22(6):589-601

Schädlich A, Kempe S, Mäder K (2014) Non-invasive in vivo characterization of microclimate ph inside in situ forming PLGA implants using multispectral fluorescence imaging. J Control Release 179:52-62

Shen X, Shamshina JL, Berton P, Gurau G, Rogers RD (2016) Hydrogels based on cellulose and chitin: fabrication, properties, and applications. Green Chem 18(1):53-75

Spiller KL, Maher SA, Lowman AM (2011) Hydrogels for the repair of articular cartilage defects. Tissue Eng Part B Rev 17(4):281-299

Svensson A, Nicklasson E, Harrah T, Panilaitis B, Kaplan D, Brittberg M, Gatenholm P (2005) Bacterial cellulose as a potential scaffold for tissue engineering of cartilage. Biomaterials 26(4):419-431

Varma AJ, Kulkarni MP (2002) Oxidation of cellulose under controlled conditions. Polym Degrad Stab 77(1):25-27

Wagenknecht W, Nehls I, Stein A, Klemm D, Philipp B (1992) Synthesis and substituent distribution of na-cellulose sulphates via o-trimethylsilyl cellulose as intermediate. Acta Polym 43(5):266-269

Wang J, Wei J, Qiu J (2016) Facile synthesis of tough double network hydrogel. MRS Adv 1(27):1953-1958

Wichterle O, Lím D (1960) Hydrophilic gels for biological use. Nature 185(4706):117-118

Yang JA, Yeom J, Hwang BW, Hoffman AS, Hahn SK (2014) In situ-forming injectable hydrogels for regenerative medicine. Prog Polym Sci 39(12):1973-1986

Yang Y, Köwitsch A, Ma N, Mäder K, Pashkuleva I, Reis RL, Groth T (2016) Functionality of surface-coupled oxidised glycosaminoglycans towards fibroblast adhesion. J Bioact Compat Polym 31(2):191-207

Zhang K, Peschel D, Brendler E, Groth T, Fischer S (2009) Synthesis and bioactivity of cellulose derivatives. Macromol Symp 280(1):28-35

Zhang K, Brendler E, Geissler A, Fischer S (2011) Synthesis and spectroscopic analysis of cellulose sulfates with regulable total degrees of substitution and sulfation patterns via ${ }^{13} \mathrm{c}$ $\mathrm{nmr}$ and ft raman spectroscopy. Polymer 52(1):26-32 
Zhou HY, Chen XG, Kong M, Liu CS, Cha DS, Kennedy JF (2008) Effect of molecular weight and degree of chitosan deacetylation on the preparation and characteristics of chitosan thermosensitive hydrogel as a delivery system. Carbohydr Polym 73(2):265-273
Publisher's Note Springer Nature remains neutral with regard to jurisdictional claims in published maps and institutional affiliations. 